Original Research Paper

\title{
A Comparative Examination of Unhealthy Behaviors and Negative-LGBT Experiences among Individuals in Legal Same-Sex Marriages and in Committed Same-Sex Relationships
}

\author{
${ }^{1}$ Debarun Majumdar and ${ }^{2}$ Cheryl Rollman-Tinajero \\ ${ }^{1}$ Department of Sociology, Texas State University, \\ 601 University Drive San Marcos, TX 78666, USA \\ ${ }^{2}$ Department of Sociology, Texas A\&M University, USA
}

\author{
Article history \\ Received:28-05-2017 \\ Revised: 21-08-2017 \\ Accepted: 18-09-2017 \\ Corresponding Author: \\ Debarun Majumdar \\ Department of Sociology, \\ Texas State University, 601 \\ University Drive San Marcos, \\ TX 78666, USA \\ Email: dm28@txstate.edu
}

\begin{abstract}
Extant literature on different-sex marriage has widely demonstrated its beneficial and protective effects. Given that legal samesex marriage has been available on a state-by-state basis only since 2004 starting with Massachusetts and nationwide since 2015 after the Supreme Court Ruling on Obergefell v. Hodges, it is imperative to understand if those entering legal same-sex marriage are different from those who are not entering this institution. We identify unhealthy behaviors, such as binge drinking and not being faithful and negative LGB-experiences, such as stigma and bullying, to examine if those in legal same-sex marriage participate in these behaviors or have these experiences at different levels compared to those in committed relationships. Using a U.S. sample convenience $(\mathrm{N}=158)$, represented strongly by the state of Texas, we found that those in legal marriages participated in unhealthy behaviors and experienced negative LGB-experiences at levels lower than those in committed relationships. Results from multivariate analyses, using Poisson's regression model, indicate that being legally married as opposed to being in committed relationship reduced unhealthy behaviors and negative experiences after controlling for sociodemographic factors. We recommend further research on same-sex marriage because of its potential implications on health.
\end{abstract}

Keywords: Same-Sex, Marriage, Committed, Relationships, Comparison

\section{Introduction}

Same-sex marriage has been an important and controversial political and social issue across the United States, especially in the last decade when two landmark United States Supreme Court (SCOTUS) verdicts conferred federal recognition to all same-sex marriages. While same-sex marriage had been legal in some states, like Massachusetts and New York, on June 26th of 2013 (Windsor v. United States), SCOTUS struck down the federal Defense of Marriage Act (DOMA). This move by SCOTUS afforded federal level recognition of same-sex marriages performed in states where it was already legal and accorded federal rights, like filing joint taxes and sponsoring permanent residency for non-U.S. spouses. In June of 2015, in another landmark decision (Obergefell v. Hodges, 2015), SCOTUS made same-sex marriage legal in all of the United States. This decision marked equal marital rights for same-sex couples in all of the United States for the first time in history. While there has been legal progress, recent public opinion surveys have found that support for same-sex marriage has been higher than ever in the U.S. According to Gallup (2015), a solid majority of Americans supported legal recognition of same-sex marriage $(60 \%)$, which is a remarkable increase from only $27 \%$ in 1996 . Thus, there is little doubt that the Lesbian, Gay, Bisexual and Transgender (LGBT) community has seen unprecedented progress in the area of marital equality in the U.S. within the last decade. This progress has also led to an increase in same-sex marriages in the U.S. There were less than 50,000 legally married same-sex couples in the U.S. in 2004 but by October of 2015, just after same-sex marriage became available nationwide, 
that number had risen to almost half a million (Badgett and Herman, 2013; Gates and Brown, 2015). With this rapid rise, interest in same-sex marriage has been growing steadily, but not much is known about those who are legally married in the U.S. While there is an impressive body of work on the protective and beneficial effect of different-sex marriage (commonly known as heterosexual marriage) (for example, Waite and Gallagher, 2000; Horn, 2013), there is limited knowledge on how same-sex couples who legally marry are different from those who are not married. As samesex marriage became more accessible from 2004, initially on a state-by-state basis starting with Massachusetts, we are now able to study individuals who entered legal same-sex marital unions. Still, research on this topic is relatively new in the U.S. and related data are just now being collected. In fact, a report on a search of NIH funded studies conducted through 2011 (Coulter et al., 2014) shows a dearth of funded research on samesex marriage and health, even though legal same-sex marriage has been available in some states since 2004 .

There are many areas of interest that are worthy of investigation, such as, whether those in legal same-sex marital unions differ from those who are in committed same-sex relationships, which is far more prevalent than marriage. Previous research has widely shown that those in different-sex marriages have better life outcomes than those who cohabit or remain single (e.g., Rogers et al., 2000) Additionally research shows negative outcomes for LGBT youth who were bullied because of their sexual orientation (e.g., Bontempo and D'Augelli, 2002). For these reasons we wanted to examine if those in same-sex marriages differed in unhealthy behaviors and negative LGBT-related experiences from those who are not married but are in committed relationships. We expect that individuals in same-sex marriages will have lower levels of participation in behaviors and experiences that may have less beneficial outcomes than those who are not married. Using primary data that were collected from 2014-2015, we seek to understand if those in legal same sex marriages are different from those who remain single in regard to unhealthy behaviors, such as smoking and binge drinking and negative LGBTrelated life experiences, such as, bullying and stigma related to sexual orientation.

This research is important as we compare samesexcouples who are legally married to those in committed same-sex relationships. Those in same-sex marriages can be considered as pioneers due to its very recent nature and we seek to gain an understanding of the differences that exist between these two groups: One, which accessed an institution from which they were historically barred and, the other, which is closest to being in a marriage-like situation without accessing the institution. We argue that by adopting those in committed relationships as the comparison group, instead of those who are single, will put focus on the recognition of same-sex marriage formally and help gain insight into whether those in these marriages can potentially enjoy the benefits as those in different-sex marriages do.

\section{Literature Review}

\section{Benefits of Marriage}

One of the most prevalent beliefs about the institution of marriage is that it leads to better physical and mental health. A large body of research exists outlining protections that those in different-sex marriages enjoy (for example, Bariola et al., 2015; Liu, 2009; Waite and Gallagher, 2000; Waite, 1995). Married individuals experience lower mortality rates (Waldron et al., 1996), social support and financial security (Waite, 1995) as well as reduction in risky behaviors that can lead to chronic health issues (Ali and Ajilore, 2011).

The benefits of marriage also cover a wide range of ages. Young adults who are in serious relationships, such as marriage or cohabitation, compared to those who are not, use drugs less frequently (Austin and Bozick, 2012). The health benefits of marriage even extend to those who have lost a spouse to death. Marriage is found to decrease the odds of engaging in negative behaviors for older widows, thus, demonstrating that the positive effects of marriage continue on later, sometimes much later in life (Schone and Weinick, 1998). These benefits and protections are attributed to the care of married individuals by a spouse who can monitor partner health behaviors, care for a partner when illness strikes and moderate their partner's risky behaviors (Waite and Gallagher, 2000; Ali and Ajilore, 2011; Averett et al., 2013). In the same vein, adherence to treatment, lowered psychological distress and bolstered immunity may be attributed to marriage as research has also shown the positive effect of marriage on cancer survivorship among different-sex couples (Aizer et al., 2013).

What makes marriage unique among all relationship types is the fact that no other relationship produces benefits as marriage does-not even cohabitation. Cohabitation among adults in different-sex relationships in the U.S. confers some marriage-like benefits such as social support and informal health support (Ross and Mirowsky, 2002), but it still falls short of the benefits of marriage (Cherlin, 2013). One recent study on the impact of marriage, either same-sex marriage or different-sex marriage, found that those who cohabit have higher levels of alcohol use (Reczek et al., 2014). This finding demonstrates that the differences in risky behavior may be in marital status and not the sexual orientation of the individuals in the relationship. One reason for the differences in behavior based on marital status may be that cohabiting different-sex partners report and exhibit lower levels of commitment to the relationship when compared to their married counterparts (Wilson and 
Oswald, 2005; Cherlin, 2009). Lower levels of commitment can lead to behaviors that are more like those of single people which can negate the protections seen in different-sex marriages (Rindfuss and VandenHeuvel, 1990). One such behavior for differentsex cohabiting couples is that they do not pool income the same way that married couples do (Winkler, 1997) thereby not realizing the psychological benefits associated with financial stability. Thus, as different-sex marriages confer many advantages, do these advantages extend to individuals in same-sex marriages?

\section{Marital Benefits and Same-Sex Marriage}

Even though it is a relatively recent phenomenon in the US, as mentioned earlier, same-sex marriage has slowly been available to LGBT citizens on a state-bystate basis since the early 2000s culminating in nationwide availability in June of 2015. Thus, it is important to understand whether benefits and protections stemming from marriage are being realized for this population. Due to the recent legalization of same-sex marriage, there is limited, but a steadily growing number, of studies that have examined its effect on the lives of LGBT people (Bariola et al., 2015; Wight et al., 2013; 2012; Riggle et al., 2010; Dee, 2008; Mathy et al., 2003). Some studies have shown that relationships benefit partners in same-sex dyads. Yet, these studies are very few and usually utilize small samples, especially when compared with the existing body of literature on different sex marriage. For example, individuals in legal same-sex marriage, compared to those who are not married, have lower levels of suicidality, psychological distress, depressive symptoms, stress, internalized homophobia and higher levels of positive affect (Bariola et al., 2015; Wight et al., 2013; 2012; Riggle et al., 2010; Dee, 2008; Mathy et al., 2003). Data from U.S. and Canada revealed that being in same-sex relationships that are marital or committed had a generally protective effect on suicidality (Mathy et al., 2003). Another study from Australia indicated that those in same-sex relationships, that were formalized through marriage or other ceremonies, experienced lower levels of psychological distress compared to those who did not (Bariola et al., 2015). Similar results were also found in a study conducted in California where legally married same-sex couples experienced lower levels of psychological distress compared to unmarried couples (Wight et al., 2013). Another U.S. study with a sample of gay-identified males in their midlife or older, showed that those married had lower odds of experiencing depressive symptoms compared to those not married. In the same study, those who were married also had higher odds of having positive affect or good mood (Wight et al., 2012). One of the few studies on same-sex relationships with a large national-level U.S. sample of over 2,000 respondents found that married individuals reported reduced levels of stress, depressive symptoms and internalized homophobia and reported a higher sense of meaning of life compared to those who were in non-marital committed relationships (Riggle et al., 2010). This was the only study to date to our knowledge that compared those who are married to those who are in committed relationships whereas most studies compare married individuals to those who are single. However, since this study was conducted prior to 2013 before DOMA was struck down, it did not include those who became beneficiaries of federal marital rights. Further, panel data from the World Health Organization (WHO) indicated that nations where same-sex partnerships were legal experienced reductions in the level of syphilis by as much as $43 \%$ (Dee, 2008).

\section{Present Study}

While studies reviewed in preceding sections have demonstrated the beneficial effects of marriage, primarily different-sex, research on legal same-sex marriage is emergent. To date, there are few studies that have compared participation in unhealthy behaviors, like binge drinking or smoking, between those in legal samesex marriage and those in committed relationships. There is a lack of research that distinguishes experiencing bullying and stigma, which are common in the LGBT community, between those who are legally married and those in committed relationships. As past literature strongly suggests sexual minority victimization from bullying and stigma is associated with depression, low self-esteem and internalized homo-negativity (Burton et al., 2013; D'Augelli et al., 2002). In our study, we seek to understand if negative LGBT-related experiences occur at different levels for those who legally marry compared to those who do not. There are very few studies, only one to our knowledge (Riggle et al., 2010), that have examined specifically those legally married and those in committed relationships. We feel that making this distinction is important in understanding the impact of legal marriage on individuals in same-sex marriages. We identify these gaps in the existing literature, which our study is seeking to fill.

Thus, we seek to answer the following research questions in this study: Do those in same-sex marriages have different levels of participation in unhealthy behaviors than those in committed relationships? Do those in legal same-sex marriages encounter negative LGBT-related experiences at different levels compared to individuals in committed relationships? We know that individuals in different-sex marriages enjoy protective effects leading to lower usage of drugs, lower levels of mortality and healthier lifestyles (Waldron et al., 1996; Ali and Ajilore, 2011; Waite, 1995). The limited literature on same-sex marriage has shown lower levels of suicidality, psychological distress and internalized homophobia among the marrieds as opposed to those who are not (Bariola et al., 2015; Wight et al., 2013; 2012; Riggle et al., 2010; Dee, 
2008; Mathy et al., 2003). Based on these findings, we expect that those who are in same-sex marriages to possess indicators that signal better future outcomes as opposed to those who are not in these marriages.

Given that those who enter same-sex marriages can be considered as pioneers due to the recent nature of this phenomenon, we can also expect this group to be different from those who are in committed relationships. Taken together, we hypothesize that there are significant unhealthy behavioral differences between those in legalized same-sex marriages and those in committed relationships. We also hypothesize that there are significant differences in negative LGBT-related experiences between those in legalized same-sex marriages and those in committed same-sex relationships.

\section{Data and Methodology}

\section{Data Collection}

The survey, that was created by the second-listed coauthor, included questions on several unhealthy behaviors related to areas such as drinking habits and driving over the speed limit. Questions on negative LGBT-related experiences such as bullying and stigma were asked. These questions were patterned after those used in the Behavioral Risk Factor Surveillance System (BRFSS). To get background information from respondents, some basic sociodemographic questions such as age, race and education were asked. The survey was created through the web-based software Qualtrix (www.qualtrix.com) and was launched online after approval by the Texas State University IRB on October 31 of 2014 . The survey took approximately 30 minutes to complete and there was no monetary compensation provided to respondents. The last recorded response was on February 7, 2015. The survey was directed towards members of the LGBT community who were either in legally recognized same-sex unions or were in selfprofessed committed relationships. It was disseminated through various LGBT organizations such as The Human Rights Campaign, Equality Texas, LGBT News, Los Angeles Gay and Lesbian Chamber of Commerce, Gay Parent Magazine and so forth. These organizations allowed posting the survey on their social media outlets, such as Facebook, so that confidentiality of membership lists and anonymity could be maintained. Once the surveys were posted online, the posts were shared and forwarded by both the original organizations and individuals that saw the posts either as members or affiliates of the organization or friends and allies. The survey was taken by 244 individuals. Of those 244, 2 did not consent to the survey and opted out immediately. Even though the survey explicitly stated that it was for the purpose of researching same-sex relationship relationships, 14 were in different-sex relationships.
Forty-three respondents indicated that they were in neither a committed relationship nor same-sex marriage. Another 27 dropped out of the survey before completing at least half of the questions. After removing these ineligible cases we were left with an analytical sample size of 158 respondents. Almost $60 \%$ of sample came from the state of Texas.

\section{Variables}

\section{Marital Status}

Marital status is the primary variable of interest in this study. This independent variable was created by asking if the respondents were legally married or were in a committed relationship but not married. This was followed up by a question regarding the state where the marriage was performed. This verified that the relationship was in fact a legal same-sex marriage and not a civil union or a committed relationship considered or treated like a marriage by the partners. The question had three possible answers: "Committed same-sex relationship but not legally married," "legally recognized same-sex marriage," and "neither." The marital status variable was created to reflect those legally married (value of 1) or those not married but in committed relationships (0). As indicated earlier, all those who selected "neither" were removed from the dataset.

\section{Dependent Variables}

We included eleven unhealthy behavioral and negative LGBT-related experiential variables. We created binary dependent variables with 1 indicating a presence of unhealthy behavior and 0 indicating its absence. A value of 1 means "yes," as opposed to "no" $(0)$, to not exercising, smoking, using drugs and having been unfaithful to a partner (There are distinct differences in intimate, sexual, relationships between gay men, lesbians and heterosexuals. An early comparative study of such differences reported that $65 \%$ of gay men and $23 \%$ of lesbian couples in America had some form of mutual non-monogamous relationship compared to between 15 and $28 \%$ of heterosexual couples, Blumstein and Schwartz, 1983). More recently, a study of Canadian gay men found that $26 \%$ reported being exclusively monogamous in their relationships (Adam, 2006)). A value of 1 may also mean consuming fast food, texting while driving, driving over the speed limit, tanning and having experienced bullying because of sexual orientation sometimes as opposed to rarely (0). These variables were recoded where "sometimes," "often" or "all of the time" reflects generally sometimes and "never," or "rarely" reflects generally rarely. In some instances, variables 
were recoded where "once a week," "2-3 times a week" and "daily" reflects generally sometimes (1) and "2-3 times a month," "once a month" and "never" reflects generally rarely $(0)$.

We created a dichotomous variable indicating binge drinking from the question that asked respondents how many drinks they consumed on average when they would drink. The responses ranged from 0 to 30 drinks with the mean number of drinks of 3.36 for the sample. The National Institute on Alcohol Abuse and Alcoholism, a branch of the National Institutes of Health (2012), defines binge drinking as more than 4 drinks for women and more than 5 drinks for men. In our study binge drinking is indicated by a value of 1 that represents more than 4 drinks consumed on average at a time and a value of 0 that represents less than 4 drinks.

Stigma was measured from four separate questions where experiences related to sexual orientation-based stigma at four different stages of life were asked. The stages were childhood, adolescence, young adulthood and adulthood. These questions that had binary responses "yes (1)" and "no (0)" were first summated to create a measure with values ranging from zero to four.

A value of zero indicates that a respondent did not experience stigma at any stage of life and a value of four indicates that a respondent experienced stigma in all four stages of life. Then, a dichotomous variable was created with a value of 1 indicating experience with sexualorientation based stigma in at least one life stage and a value of 0 indicating no experience with stigma in any of the specified life stages.

We created a count measure of unhealthy behaviors and negative LGBT-related experiences by summating the eleven preceding dichotomous outcomes. This count variable has values ranging from 0 through 11 . This variable measures the number of unhealthy behaviors and negative-LGBT related experiences for the respondents with higher values representing higher levels of the variable. As this measure combines an array of behaviors and experiences, for simplicity, we refer to them as Unhealthy Behaviors and Negative Experiences (UBNEs). We realize that this measure consists of disparate items such as tanning, using drugs and being bullied. Yet, given the dearth of studies comparing those who are in legal same-sex marriages and committed relationships, we decided to capture as many items as possible that reflects some level of risk taking or negative experiences.

The data contained sociodemographic variables: Age, education, race/ethnicity and sex. Age variable has ordered categories ranging from one (18-29) through 7 (60-69). Respondent education level also has ordered categories ranging from one (high school level or below) through five (doctoral level). Those who indicated education level as "other" were excluded from analysis.
The values of age and education are ordered, with higher values indicating higher levels of the variables and they are treated as continuous variables. Race and ethnicity of respondents are indicated by six categories: Caucasian, African American, Hispanic, Asian, Native American and Multiracial/other. As the sample was predominantly Caucasian with low numbers in the remaining categories, we created a dichotomized variable to reflect whites (1) and non-whites (0).

The sex of respondents is indicated by female (1) and male (0).

\section{Analytical Strategy}

In order to determine if there was a relationship between unhealthy behaviors and negative LGBT-related experiences with marital status, several bivariate chisquare analyses were performed. We performed a difference test (t-test) to examine if the mean levels of UBNEs varied significantly between those married and those in committed relationships.

These analyses assessed behavioral and negative experiential differences between those in legal same-sex marriage and those in committed relationships.

We employed Poisson's regression model to predict UBNEs by marital status. Because Poisson's regression has a restrictive equidispersion assumption $\left(\mu=\sigma^{2}\right)$ (Haller, 2011; Long, 1997), we first checked if negative binomial regression, which does not require this assumption, is suitable. As negative binomial regression is appropriate for overdispersed count data, we checked for overdispersion of the distribution of UBNEs. The mean of UBNEs (4.05) and its variance (2.03), although not equal, were close to one another, which indicates overdispersion may not be a problem with our data. Further, when we ran negative binomial regression, the likelihood test for the dispersion parameter (alpha) was not statistically significant. This indicated no improvement in fit with using negative binomial regression over Poisson's regression model. The value of alpha was almost zero $(1.73 \mathrm{e}-18 ; \mathrm{p}>0.05)$ and the coefficients of negative binomial and Poisson's regressions were virtually the same. Upon visual inspection of the UBNEs distribution using bar chart, we also observed that overdispersion was not present. These steps, which are recommended (see Long, 1997; Cameron and Trivedi, 1986) gave us confidence that Poisson's regression modeling is a suitable technique for our data (We performed ordered logistic regression by treating the UBNEs as an ordinal variable. The effect of marital status on UBNE was similar to that in Poisson regression model. Results available upon request. We used an option to obtain robust standard errors in STATA as suggested by Cameron and Trivedi (2009) to offset possible violations of model assumptions). We first ran the regression with marital status as the 
predictor of UBNEs. Then, we added sociodemographic variables to check if the relationship between marital status and UBNEs persisted after controlling for age, education level, race and sex (We did not use duration of marriage to account for its confounding effect on the dependent variables because of missing information on almost a quarter of the sample. However, when we ran Poisson's regression model only with valid duration data, the relationship between UBNEs and marital status was significant $(p<0.05)$. When we substituted missing duration data with the median and included a dummy variable flagging those missing and then ran PRM, the relationship between UBNEs and marital status was significant $(p<0.05)$. Results available upon request. As a substantial part of the sample came from Texas, we ran the multivariate analysis by introducing a dummy variable indicating Texas residents. The results remained virtually unchanged. The results of Poisson's regression model presented are runs without this dummy variable. PRM with the Texas dummy variables available upon request). As females and males overwhelmingly identified as lesbians and gay males respectively in our sample, sexual orientation was not included as a control variable as it would duplicate the sex variable.

Due to a small sample size, we are not making a distinction between marginally significant effects at assumed significance level $(\alpha)$ at 0.10 and conventional significance level of 0.05 . We are setting significance at assumed level of 0.10 .

\section{Results}

\section{Univariate Analysis}

The sample consisted of 100 participants who identified as lesbians, 33 identified as gay men, 17 as bisexuals and 8 of the participants identified as other sexual orientation (Table 1). About $67 \%$ of the sample was not married and the rest were married. Another $75 \%$ did not have children. The modal age range was from 30 to 39 with about $50 \%$ of the respondents in this age group. About $72 \%$ of the respondents identified as Caucasian, nearly $13 \%$ as multiracial or as "other," $12 \%$ identified as Hispanic, slightly over $2 \%$ identified as Asian and just over 1\% identified as African American. Just under half of the sample had some college education, $28 \%$ had at least a college degree and about $24 \%$ had high school education or less. The majority of respondents had a combined household income between $\$ 41,000$ and $\$ 100,000$ before taxes in 2013. Similar demographic patterns were observed upon breaking down the sample by marital status: Committed relationship and legally married.

Table 1. Description of sample

\begin{tabular}{|c|c|c|c|c|}
\hline & Committed $(\%)^{2}$ & Married $(\%)^{2}$ & Total Sample $(\%)$ & $\mathrm{N}$ \\
\hline \multicolumn{5}{|l|}{ Sexual Orientation } \\
\hline Lesbian & 58.1 & 72.5 & 63.3 & 100 \\
\hline Gay Male & 22.9 & 17.6 & 20.9 & 33 \\
\hline Bisexual & 12.4 & 7.8 & 10.8 & 17 \\
\hline Other & 6.7 & 2 & 5.1 & 8 \\
\hline \multicolumn{5}{|l|}{ Age } \\
\hline $18-29$ & 27.6 & 15.7 & 23.4 & 37 \\
\hline $30-39$ & 44.8 & 60.8 & 50.6 & 80 \\
\hline $40-49$ & 21 & 17.6 & 19.6 & 31 \\
\hline $50-59$ & 5.7 & 5.9 & 5.7 & 9 \\
\hline $60-69$ & 1 & 0 & 0.6 & 1 \\
\hline \multicolumn{5}{|l|}{ Education } \\
\hline High school or below & 1 & 5.9 & 2.5 & 4 \\
\hline Some College & 27.6 & 9.8 & 21.5 & 34 \\
\hline College degree & 44.8 & 52.9 & 48.1 & 76 \\
\hline Master's degree & 17.1 & 23.5 & 19 & 30 \\
\hline $\mathrm{PhD}$ & 5.7 & 3.9 & 5.1 & 8 \\
\hline Other & 3.8 & & 3.8 & 6 \\
\hline \multicolumn{5}{|l|}{ Race } \\
\hline Caucasian & 72 & 70.6 & 71.5 & 113 \\
\hline African American & 0.9 & 2 & 1.3 & 2 \\
\hline Hispanic & 12.1 & 11.8 & 12 & 19 \\
\hline Asian & 1.9 & 3.9 & 2.5 & 4 \\
\hline Native American & 0 & 0 & 0 & 0 \\
\hline Multiracial/other & 13.1 & 11.8 & 12.7 & 20 \\
\hline \multicolumn{5}{|l|}{$\operatorname{Sex}^{I}$} \\
\hline Female & 74.3 & 80.4 & 76.8 & 121 \\
\hline Male & 23.8 & 15.7 & 21.4 & 33 \\
\hline
\end{tabular}

Data collected between 2014-2015; $\mathrm{N}=158$;

${ }^{1}$ Percentages not equal to $100 \%$ due to missing data

${ }^{2} \mathrm{~N}($ committed relationships $)=105 ; \mathrm{N}($ legally married $)=51$; data on marital status missing for 2 cases 


\section{Risky Behaviors and Marital Status}

The results in Table 2 indicate that those legally married generally engaged in unhealthy behaviors at lower levels than those who are in committed relationships. Only in three unhealthy behaviors did married individuals exhibit higher levels of participation than those in committed relationships: Fast food intake, speeding and tanning. In the remaining, those married exhibited lower levels of participation compared to those who are in committed relationships. Also, a significantly lower percentage of marrieds were unfaithful to their partners (3.9\%) compared to those in committed relationships $(16.2 \%)$. Thus, it appears that those who were married engage in unhealthy behaviors to a lesser extent than those who were in relationships. The results indicate that most of these differences are not statistically significant. We recommend testing these differences using larger samples.

Results also reveal statistically significant differences in negative LGBT-related experiences among those who are married and those who are in committed relationships. Those who were married indicated having experienced bullying at lower levels (20.4\%) compared to those who were in committed relationships (35\%). Finally, lower levels of those married (72.5\%) experienced stigma at some point in their lives compared to those in relationships (86.7\%). These findings indicate that bullying and stigma were common experiences for this sample.

We also considered the unhealthy behaviors and negative LGBT-related experiences in totality by creating a summative count measure (UBNEs). Our data reveals that those married had significantly lower levels of UBNEs compared to those who were in committed relationships.
Those married had 3.60 UBNEs on the average compared to 4.28 for those in committed relationships.

From the preceding bivariate results, it appears that those who were legally married participated in unhealthy behaviors or had negative life experiences at lower levels than those who were in committed relationships. These findings are similar to data on different-sex couples that have found beneficial and protective effects of marriage (Liu, 2009; Waite, 1995). Our findings also add to and align with the limited studies on same-sex marriage that has shown that those in marriages experience lower levels of psychological distress and internalized homophobia (Wight et al., 2013).

\section{Multivariate Analysis}

To increase confidence in our findings, we performed regression analyses to predict Unhealthy Behaviors and Negative Experiences (UBNEs) by marital status. As UBNE is a count measure, we performed Poisson's regression modeling. We also controlled for various relevant sociodemographic characteristics to ascertain that the significant relationship between UBNEs and marital status persisted (Table 3). The results indicate a significant negative relationship between the number of UBNEs and marital status. By exponentiating coefficients, we are able to achieve an intuitive percentage change interpretation. Thus, as per the first model with only the marital status predictor, being married, as opposed to being in a committed relationship, corresponds almost to a $16 \%$ decrease in UBNEs. The effect of marital status on UBNEs remains essentially the same after controlling for age, education, race/ethnicity and gender.

Table 2. Participation in Unhealthy Behaviors and Negative Experiences (UBNEs) by Relationship Status

\begin{tabular}{|c|c|c|c|}
\hline Unhealthy behavior $^{1}(\%)$ & Committed relationship & Legally married & $\mathrm{N}^{3}$ \\
\hline No exercise & 26.7 & 15.7 & 156 \\
\hline Fast food & 59.6 & 65.3 & 153 \\
\hline Texting while driving & 36.5 & 30.6 & 153 \\
\hline Speeding & 76.0 & 83.7 & 153 \\
\hline Tan & 14.4 & 20.4 & 153 \\
\hline Smoke & 17.1 & 7.8 & 156 \\
\hline Drugs & 38.1 & 33.3 & 156 \\
\hline Drink & 17.0 & 8.7 & 134 \\
\hline Unfaithful** & 16.2 & 3.9 & 156 \\
\hline Stigma $* *$ & 86.7 & 72.5 & 156 \\
\hline Bully* & 35.0 & 20.4 & 152 \\
\hline UBNE (mean $)^{2} * *$ & 4.28 & 3.6 & 131 \\
\hline
\end{tabular}

Data collected between 2014-2015; ${ }^{*} \mathrm{p} \leq 0.10,{ }^{* *} \mathrm{p} \leq 0.05,{ }^{* * *} \mathrm{p} \leq 0.01$;

${ }^{I}$ Chi-square tests unless otherwise indicated

${ }^{2}$ Independent samples T-test

${ }^{3} \mathrm{Ns}$ lower than total sample size due to deletion of cases with missing data 
Table 3. Poisson's regression model predicting Unhealthy Behaviors and Negative Experiences (UBNEs)

\begin{tabular}{lllllll}
\hline & Coefficients & S.E. & \% Change & Coefficients & S.E. & \% Change $^{1}$ \\
\hline Married & $-0.17^{* *}$ & 0.07 & -15.6 & $-0.18^{* *}$ & 0.07 & -16.4 \\
Age & & & & -0.01 & 0.03 & \\
Education & & & -0.02 & 0.07 & \\
White & & & 0.08 & 0.08 & \\
Female & & & & -0.07 & 0.08 & \\
Constant & $1.45^{* * *}$ & 0.04 & & $1.49^{* * *}$ & 0.13 & \\
$\mathrm{~N}^{2}$ & & 131 & & & 115 & \\
\hline
\end{tabular}

Data collected between 2014-2015; * $\mathrm{p} \leq 0.10,{ }^{* *} \mathrm{p} \leq 0.05, * * * \mathrm{p} \leq 0.01$

${ }^{1}$ Percent change reported only for significant predictors

${ }^{2} N$ s lower than total sample size due to deletion of cases with missing data

\section{Conclusion}

The aim of this research was to assess if individuals in legal same-sex marriages were different from those in self-professed committed relationships in unhealthy behaviors and negative LGBT related experiences. We believe that our research is important because there is limited research on same-sex marriages and about individuals who enter these marriages as same-sex marriage is a very recent phenomenon. Do these trailblazers participate in unhealthy behaviors at lower levels compared to those who are not married? Do they have negative LGBT-related experiences at lower levels compared to those who are not married? There is a large body of research that has shown that those in differentsex marriages have better health outcomes than those who are single; e.g., those in different sex marriages enjoy lower levels of mortality, which could be attributed to healthier lifestyle and strong social and financial support (e.g., Waite and Gallagher, 2000; Horn, 2013). Although not as extensively studied as differentsex marriages due to its relatively recent recognition, some studies have shown benefits of same-sex marriages, such as lower levels of suicidality, psychological distress and internalized homophobia (Wight et al., 2013; Riggle et al., 2010). Thus, we hypothesized that there will be significant differences in unhealthy behaviors between those in legal same-sex marriages and those in committed same-sex relationship. We also hypothesized that those in legal same-sex marriages will have significantly different levels of negative LGBT-related experiences.

Our hypotheses are supported by the data. Those who are legally married engaged in unhealthy behaviors at lower levels than those in committed relationships, except for in fast food intake, driving more than 5 miles over the posted speed limit and tanning. The relationship between unfaithfulness and marital status was statistically significant. Those who were married exhibited lower levels of unfaithfulness compared to those in committed relationships. The relationship between marital status and having experienced bullying or stigma because of sexual-orientation was also significant. The marrieds experienced bullying and stigma at significantly lower levels than those in committed relationships. Importantly, when we considered all unhealthy behaviors and negative LGBTrelated experiences together to create a summative measure (UBNEs), we found that those who were married had significantly lower levels of UBNEs compared to those who were in committed relationships. Further, results from multivariate analysis indicated that being legally married status, as opposed to being in committed relationships, corresponded to significant decreases in UBNEs after controlling for background sociodemographic characteristics.

\section{Discussion}

Thus, our study indicates that those who are married appear to engage in unhealthy behaviors to a lesser extent than those who are not legally married. Although it is early to conclude that same-sex marriage will mirror different-sex marriage, the findings from this study appear to align with the general consensus on the benefits and protective effects of marriage. Our findings are also in line with the limited literature on same-sex marriage that has found beneficial and protective effects of same-sex marriage (Wight et al., 2012; Riggle et al., 2010). However, more research needs to be conducted on this topic as it is a relatively new phenomenon with important implications on the health of members of the LGBT community.

There are several implications of our study. As the path to legal same-sex marriage has been paved through acrimonious debates in which anti-marriage advocates have played up negative LGBT stereotypes, it is important to understand who the vanguards of same-sex marriage are. Further, in a social environment where prejudices towards and discrimination of LGBT people are rampant, it is important to gain an understanding of the individuals in same-sex unions who are choosing to enter the ancient institution of marriage. Our findings suggest that the pioneers of same-sex marriage may be poised for better future outcomes than those who are not married. As different-sex couples have better health and psychological outcomes (e.g., Liu, 2009; Rogers et al., 2000), per our results, having lower levels of unhealthy 
behaviors and negative LGBT-related experiences, may place individuals in same-sex marriage in the same trajectory. As same-sex marriage is still a relatively new phenomenon, we are unable to predict better future outcomes with certainty, but this also points to the necessity of further research using longitudinal data to corroborate the findings.

There are several limitations to this study. Due to the cross-sectional nature of our data, we cannot infer causality in the association between unhealthy behaviors and negative LGBT-related experiences with same-sex marriage. However, the relationship with experiencing bullying and sexual stigma warrant discussion because these experiences could have preceded the event of marriage-especially experiences during pre-adolescence, teenage years and young adulthood which may carry negative effects into adulthood (Rivers, 2001). These life stage experiences with sexual stigma and bullying indicate a need for research on who, in the LGBT community, gets married as selectivity may be present. Yet, some studies on the benefit of marriage indicate that relationship between marriage and outcomes, such as, psychological health, go beyond selection effects (Hope et al., 1999; Kim and McKenry, 2002; Lamb et al., 2003). Our recommendation is for a case-control study design predicting marriage with independent variables, such as childhood experiences with bullying or stigma, that are antecedent to the dependent variable as these experiences can have long lasting effects (Bontempo and D'Augelli, 2002; Rivers, 2001). As this study does not attempt to draw causal inferences, this is not a major issue and implications from the findings are still reasonable and valid. This study also uses a relatively small sample of convenience with a substantial segment from the state of Texas. Thus, this precludes any generalization of the results and our recommendation for future studies is to draw samples that are larger and have greater representation of various races, ethnicities, sexes and socioeconomic statuses among other attributes, similar to data that can be found in the National Health Interview Survey (NHIS) or National Survey of Family Growth (NSFG). Despite these limitations, we believe our study contributes to the limited literature on legal same-sex marriage and is one of the few to compare individuals in these marriages with those who are in committed relationships.

\section{Acknowledgement}

The authors would like to thank the anonymous respondents for their willingness to participate in this study. The authors would also like to thank the anonymous reviewers for their insightful comments on previous versions of the paper.

\section{Author's Contributions}

Debarun Majumdar: Developed analytical strategy, analyzed data, and drafted manuscript.

Cheryl Rollman-Tinajero: Created survey questionnaire, collected data, and conducted literature review.

\section{Ethics}

This study was conducted with the approval of the Institutional Review Board at Texas State University. Survey responses from anonymous participants were kept highly confidential.

\section{References}

Adam, B.D., 2006. Relationship innovation in male couples. Sexualities, 9: 5-26.

Ali, M.M. and O. Ajilore, 2011. Can marriage reduce risky health behavior for African Americans? J. Family Economic Issue, 32: 191-203. DOI: $10.1007 / \mathrm{s} 10834-010-9242-\mathrm{z}$

Austin, E. and R. Bozick, 2012. Partnership formation and substance use in the transition adulthood. J. Youth Adolescence, 41: 167-178.

Averett, S.L., L.M. Argys and J. Sorkin, 2013. In sickness and in health: An examination of relationship status and health using data from the Canadian national public health survey. Rev. Economics Household, 11: 599-633. DOI: $10.1007 / \mathrm{s} 11150-012-9143-\mathrm{z}$

Ayal A.A., M.H. Chen, E.P. McCarthy, M.L. Mendu and Sophia Koo et al., 2013. Marital status and survival in patients with cancer. J. Clinical Oncology, 31: 3869-3876. DOI: 10.1200/JCO.2013.49.6489

Badgett, M.V. and J.L. Herman, 2013. Patterns of Relationship Recognition by Same-Sex Couples in the United States. In: International Handbook on the Demography of Sexuality, Baumle, A.K. (Ed.)., Dordrecht: Springer Publications, pp: 331-355.

Bariola, E., A. Lyons and W. Leonard, 2015. The mental health benefits of relationship formalisation among lesbians and gay men in same-sex relationships. Australian New Zealand J. Public Health, 39: 530-535. DOI: 10.1111/1753-6405.12432

Blumstein, Philip and Pepper Schwartz, 1983. American Couples: Money - Work - Sex. New York: William Morrow.

Bontempo, D. and A. D'Augelli, 2002. Effects of atschool victimization and sexual orientation on Lesbian, Gay, or bisexual youths' health risk behavior. J. Adolescent Health, 30: 364-374. DOI: $10.1016 / \mathrm{S} 1054-139 \mathrm{X}(01) 00415-3$ 
Burton, C.M., M.P. Marshal, D.J. Chisolm, G.S. Sucato and M.S. Friedman et al., 2013. Sexual minorityrelated victimization as a mediator of mental health disparities in sexual minority youth: A longitudinal analysis. J. Youth Adolescence, 42: 394-402.

DOI: /10.1007/s10964-012-9901-5

Cameron, A.C. and P.K. Trivedi, 1986. Econometric models based on count data: comparisons and applications of some estimators and tests. J. Applied Econ., 1: 29-53. DOI: 10.1002/jae.3950010104

Cameron, A.C. and P.K. Trivedi, 2009. Microeconometrics Using Stata. College Station, TX: Stata Press.

Cherlin, A.J., 2009. The marriage-go-round: The state of marriage and the family in America today. New York: Alfred A. Knopf.

Cherlin, A.J., 2013. Health, marriage and same-sex partnerships. J. Health Social Behavior, 54: 64-66. DOI: $10.1177 / 0022146512474430$

Coulter, R.W.S., K.S. Kenst, D.J. Bowen and Scout, 2014. Research funded by the national institutes of health on the health of lesbian, gay, bisexual and transgender populations. Am. J. Public Health, 104: e105-e112. DOI: 10.2105/AJPH.2013.301501

D'Augelli, A., N. Pilkington and S. Hershberger, 2002. Incidence and mental health impact of sexual orientation victimization of Lesbian, gay and bisexual youths in high school. School Psychol. Quarterly, 17: 148-167.

DOI: $10.1521 /$ scpq.17.2.148.20854

Dee, T., 2008. Forsaking all others? The effects of samesex partnership laws on risky sex. Econ. J., 118: 1055-1078.

DOI: $10.1111 / \mathrm{j} .1468-0297.2008 .02160 . \mathrm{x}$

Defense of Marriage Act, Pub L No. 104-199, Stat. 2419, 1996.

Gallup, 2015. Record-High $60 \%$ of Americans support same-sex marriage.

Gates, G.J. and T. Brown, 2015. Marriage and same-sex couples after obergefell. The Williams Institute.

Haller, W., 2011. Dreams fulfilled, dreams shattered: determinants of segmented assimilation in the second generation. Social Forces, 89: 733-762. DOI: $10.1353 /$ sof.2011.0003

Hope, S., B. Rodgers and C. Power, 1999. Marital status transitions and psychological distress: Longitudinal evidence from a national population sample. Psychological Med., 29: 381-389. DOI: $10.1017 / \mathrm{S} 0033291798008149$

Horn, E.E., 2013. Accounting for the Physical and mental health benefits of entry into marriage: A genetically informed study of selection and causation. J. Family Psychol., 27: 30-41.

DOI: $10.1037 / \mathrm{a} 0029803$
Kim, H. and P. McKenry, 2002. The relationship between marriage and psychological wellbeing: A longitudinal analysis. J. Family Issues, 23: 885-911. DOI: $10.1177 / 019251302237296$

Lamb, K.A., G.R. Lee and A. DeMaris, 2003. Union formation and depression: selection and relationship effects. J. Marriage Family, 65: 953-962. DOI: $10.1111 /$ j.1741-3737.2003.00953.x

Liu, H., 2009. Till death do us part: Marital status and U.S. mortality trends, 1986-2000. J. Marriage Family, 71: 1158-1173. DOI: $10.1111 /$ j.1741-3737.2009.00661.x

Long, J.S., 1997. Regression models for categorical and limited dependent variables. Thousand Oaks: Sage Publications.

Mathy, R.M., S.K. Kerr and B.A. Lehmann, 2003. Mental health implications of same-sex marriage: Influences of sexual orientation and relationship status in Canada and the United States. J. Psychol. Human Sexuality, 15: 117-141.

Behavioral Risk Factor Surveillance System. "About the Behavioral Risk Factor Surveillance System (BRFSS).

National Institute on Alcohol Abuse and Alcoholism. 2012. Alcohol Facts and Statistics.

Obergefell v. Hodges, 2015. SCOTUSblog.

Reczek, C., H. Lui and R. Spiker, 2014. A population based study of alcohol use in same-sex and different-sex unions. J. Marriage Family, 76: 557-572. DOI: $10.1111 /$ jomf.12113

Riggle, E., S. Rostosky and S. Horne, 2010. Psychological distress, well-being and legal recognition in same-sex couple relationships. J. Family Psychol., 24: 82-86. DOI: 10.1037/a0017942

Rindfuss, R.R. and A. VandenHeuvel, 1990. Cohabitation: A precursor to marriage or an alternative to being single? Population Development Rev., 16: 703-726.

Rivers, I., 2001. The bullying of sexual minorities at school: its nature and long-term correlates. Educ. Child Psychol., 18: 32-46.

Rogers, R.R.H. and C. Nam, 2000. Living and dying in the USA: Behavioral, health and social differentials of adult mortality. San Diego: Academic Press.

Ross, C.E. and J. Mirowsky, 2002. Family relationships, social support and subjective life expectancy. J. Health Social Behav., 43: 469-489. DOI: $10.2307 / 3090238$

Schone, B. and R. Weinick, 1998. Health-related behaviors and the benefits of marriage for elderly persons. Gerontologist 38 (5): 618-627. DOI: $10.1093 /$ geront $/ 38.5 .618$

Waite, L. and M. Gallagher, 2000. The case for marriage: Why married people are happier, healthier and better off financially. New York, NY: Broadway Books. 
Waite, L.J., 1995. Does marriage matter? Demography, 32: 492-507. DOI: 10.2307/2061670

Waldron, I., M.E. Hughes and T.L. Brooks, 1996. Marriage protection and marriage selection: Prospective evidence for reciprocal effects of marital status and health. Soc. Sci. Med., 43: 113-123. DOI: $10.1016 / 0277-9536(95) 00347-9$

Wight, R.G., A.J. LeBlanc and M.V. Lee Badgett, 2013. Same-sex legal marriage and psychological wellbeing: Findings from the california health interview survey. Am. J. Public Health, 103: 339-346.

DOI: 10.2105/AJPH.2012.301113

Wight, R.G., A.J. LeBlanc, B. de Vries and R. Detels, 2012. Stress and mental health among midlife and older gay-identified men. Ame. J. Public Health, 102: 503-510. DOI: 10.2105/AJPH.2011.300384
Wilson, C.M. and A.J. Oswald, 2005. How does marriage affect physical and psychological health? A survey of the longitudinal evidence. Working Paper. Coventry: University of Warwick, Department of Economics.

Windsor v. United States. Petition for Certiorari Denied, 2013. SCOTUS blog.

Winkler, A.E., 1997. Economic decision-making by cohabiters: Findings regarding income pooling. Applied Econ., 29: 1079-1090.

DOI: $10.1080 / 000368497326471$ 